\title{
Electrochemical Response of Platinum Ultrathin Layer Formed by Pulsed Laser Deposition
}

\author{
Takeshi Ito, ${ }^{1}$ Satoru Kaneko, ${ }^{1}$ Masayuki Kunimatsu, ${ }^{1}$ Yasuo Hirabayashi, ${ }^{1}$ \\ Masayasu Soga, ${ }^{1}$ and Koji Suzuki ${ }^{2}$ \\ ${ }^{1}$ Kanagawa Industrial Technology Center, Kanagawa 243-0435, Japan \\ ${ }^{2}$ Faculty of Science and Technology, Keio University, Kanagawa 223-0061, Japan
}

Correspondence should be addressed to Takeshi Ito, taito@kanagawa-iri.go.jp

Received 26 April 2011; Revised 5 July 2011; Accepted 5 July 2011

Academic Editor: Aleksandar Radu

Copyright ( 2011 Takeshi Ito et al. This is an open access article distributed under the Creative Commons Attribution License, which permits unrestricted use, distribution, and reproduction in any medium, provided the original work is properly cited.

Ultrathin layer of platinum (ULPt) was deposited on glassy carbon (GC) substrate by using pulsed laser deposition (PLD) method, and electrochemical properties of the ULPt were discussed. The deposition was simply performed at room temperature with short deposition time. Atomic force microscopy and scanning electron microscopy images showed the flat surface of the ULPt. X-ray photoelectron spectroscopy (XPS) characterized the ULPt in the Pt(0) state, and biding energy of ULPt was positively shifted. These results indicated that nanostructure of Pt thin layer was formed. The electrochemical activity of the prepared ULPt on GC substrate was superior to a bulk Pt electrode regarding the potential and the magnitude of current on oxidizing hydrogen peroxide. This fast and easily prepared low-cost electrode had the potential to replace a conventional bulk metal electrode.

\section{Introduction}

Recently, high sensitivity of palm-size biosensors is required for home medical care and point of care testing (POCT). Electrochemical detection provides to downsize a package of the sensor; however, it needs to improve the sensitivity of an electrode. Platinum (Pt) is widely used as the electrochemical material since $\mathrm{Pt}$ is a corrosion-inhibiting material with electrochemical stability. One of the biosensing applications is a detector for oxidation of hydrogen peroxide, which is generated by enzymatic reaction on oxidase-based biosensors. Many studies have been reported about the performance of Pt-based electrodes and their fabrication method for biosensing. In particular, Pt nanoparticle has great potential to improve the sensitivity and decrease the electrochemical potential on detecting hydrogen peroxide. The electrode requires the surface flatness to decrease the noise level, and highly dispersed Pt nano-particles increase active area. To meet these requirements, Pt nano-particles dispersed carbon electrode is one of the candidates.

Electrochemical deposition can prepare Pt-black electrode at low cost as a simple method [1-4]. However, it is difficult to control the particle size and dispersion. The
Pt-black electrode has high electrochemical activity with much large surface area compared to Pt bulk electrode. Since this large surface area may cause a high background current, it also provides low detection limit. Some groups reported that nanoscale Pt clusters were obtained using thermolysis of a carbon precursor with Pt particles by a chemical vapor deposition (CVD) method [5-7]. This process needs polymer synthesis skills and high temperature of $600^{\circ} \mathrm{C}$ for thermolysis. These disadvantages restrict widespread use of the Pt cluster electrode. You et al. reported an RF cosputtering method, one of physical vapor deposition (PVD) methods, for preparing a homogenous film with metal nano-particles embedded in a graphite-like carbon film $[8,9]$. This film electrode showed high sensitivity for hydrogen peroxide and low base line drift despite a low atomic content of $\mathrm{Pt}$ [8]. Variation range of sputtering ratio is narrow on the co-sputtering since the rate depended on the type of the material and the sputtering gas. Pulsed laser deposition (PLD), the same as pulsed laser ablation, is used for preparing metal nano-particles in liquid [1012]. However, it is difficult to coat the particles on the flat substrate with dispersion control. 
We reported here characterization and electrochemical properties of an ultrathin layer of Pt (ULPt) prepared by the PLD method, and its application to detect hydrogen peroxide. The PLD method is widely used to deposit a functional thin film like a superconductive solid film [13], an electrolyte film for solid oxide fuel cell (SOFC) [14], and multilayers in an atomic layer with high quality [13, $15,16]$. Quality of the film is comparable to those grown by molecular beam epitaxy (MBE). The PLD method is suitable to obtain an ultrathin layer and nanoparticles, and it has more flexibility than that of other methods as a magnetron sputtering and MBE, since the PLD method is a versatile method with wide range of the deposition pressure and the gas atmosphere. The PLD method is an extremely simple, flexible system; it is easily adaptable to different materials without the constrains imposed by use of internally powered evaporation source. However, there are few reports describing characteristics of the electrode for electrochemistry by using the PLD methods. Nanoparticles can be deposited on only topmost surface by the PLD method instead of implanting the nanoparticles in films using the cosputtering method. The PLD method has the advantages of controlling the size of nanoparticles $[17,18]$. The thickness of the thin film can be controlled with high precision by controlling the number of laser pulse. We studied the capability of Pt ultra thin film deposited by the PLD method as a high sensitive electrochemical material.

\section{Experimental Section}

2.1. Materials. Phosphate buffer solution was prepared to dissolve $1 / 15 \mathrm{M}$ phosphate buffer powder into distilled water $(\mathrm{pH}=7.0)$. The powder, sulfuric acid, and hydrogen peroxide were purchased from Wako Pure Chemical Industries, Ltd. (Osaka, Japan). Platinum tablet $(3 \mathrm{~N}$ up, diameter $=$ $10 \mathrm{~mm}$ ) as a target was obtained from Kojundo Chemical Laboratory Co., Ltd. (Saitama, Japan). Glassy carbon (GC) substrate $(20 \mathrm{~mm} \times 20 \mathrm{~mm} \times 3 \mathrm{~mm}$ thick $)$ was purchased from Tokai Carbon Co., Ltd. (Tokyo, Japan), and was diced to $10 \mathrm{~mm} \times 10 \mathrm{~mm}$ for Pt coating.

2.2. Ultrathin Layer Coating. ULPt was prepared by using a Q switched Nd:YAG laser (SL803G, Spectron Laser Systems Ltd., England) with its fourth harmonics $(266 \mathrm{~nm}$ ) operating at $2 \mathrm{~Hz}[19,20]$. The laser influence was adjusted at $2 \mathrm{~J} / \mathrm{cm}^{2}$. ULPt was deposited on the GC substrate in a custom-made stainless-steel chamber (Showa Shinku Ltd., Japan). Distance between the target and the substrate was set to $30 \mathrm{~mm}$. The target was kept swinging during the deposition in order to prevent beam damage on the target. $\mathrm{Pt}$ was deposited at room temperature in the pressure of $3 \times 10^{-3} \mathrm{~Pa}$ without gas atmosphere. We simplify a sample condition as ULPt (deposition time), and the deposition time was changed from 30 to $120 \mathrm{sec}$.

2.3. Instrumentation and Measurements. X-ray photoelectron spectroscopy (XPS; Model 5500, Ulvac-Phi, Inc., Japan) was used to estimate a quantitative composition and atomic
TABLE 1: The surface roughness (Ra) of GC substrate and ULPt electrodes, which was calculated from AFM data, when the scanning area was $3 \mu \mathrm{m} \times 3 \mu \mathrm{m}$.

\begin{tabular}{lc}
\hline Sample & $\mathrm{Ra}(\mathrm{nm})$ \\
\hline GC substrate & 2.67 \\
$\mathrm{ULPt}(30 \mathrm{~s})$ & 2.68 \\
$\mathrm{ULPt}(60 \mathrm{~s})$ & 2.72 \\
$\mathrm{ULPt}(90 \mathrm{~s})$ & 3.07 \\
$\mathrm{ULPt}(120 \mathrm{~s})$ & 2.67 \\
\hline
\end{tabular}

fractional contents. Surface morphology was observed using a field emission scanning electron microscopy (FE-SEM, Silion, FEI Company, USA). A surface roughness was measured by using an atomic force microscopy (AFM; SPI 3800, SII Nano Technology Inc., Japan) with tapping mode using am SI-DF40 cantilever. High-resolution observation of ULPt was carried out using transmission electron microscopy (TEM; JEM-2000 FX2, JEOL Ltd., Japan).

We evaluated electrochemical properties of ULPt using a potentiostat (SI1287, Solartron, UK) with a plate material evaluating cell (BAS Co., Ltd., Japan) consisting of ULPt as a working electrode $\left(\mathrm{WE}\right.$, active area $=0.48 \mathrm{~cm}^{2}$ ), a reference electrode (RE), and a Pt wire counter electrode. Reversible hydrogen electrode (RHE) and $\mathrm{Ag} / \mathrm{AgCl}(3 \mathrm{M} \mathrm{NaCl})$ electrode were used for the $\mathrm{RE}$ in $0.5 \mathrm{M}$ sulfuric acid solution and in the phosphate buffer solution, respectively. All the measurements were performed at room temperature with the sweep rate of $50 \mathrm{mV} / \mathrm{s}$.

\section{Results and Discussion}

FE-SEM image and AFM image showed flat surface of ULPt films. For example, the surface images on $\operatorname{ULPt}(90 \mathrm{~s})$ are shown in Figures 1(a): SEM and 1(b): AFM, and they were conformable with each other. In fact, there were droplets on the deposition and polishing flaws. The surface roughness (average roughness $=\mathrm{Ra}$ ) was calculated on the $3 \mu \mathrm{m} \times$ $3 \mu \mathrm{m}$ images using the software provided by the AFM probe station. Table 1 listed Ra corresponding to the deposition time. ULPt on GC had flat surface equivalent with the surface of GC substrate since the change of Ra was at sub$\mathrm{nm}$ level. Ra of ULPt increased with the deposition time from 30 to $90 \mathrm{sec}$. Maximum value of $\mathrm{Ra}$ was $3.07 \mathrm{~nm}$ at the deposition time of $90 \mathrm{sec}$, which was slightly larger than that of GC substrate. Distribution of Pt nanoparticles increased with the deposition time from TEM analysis. Figures 2(a) and 2(b) show the TEM images of ULPt(90s) and ULPt(120 s), respectively. The image of ULPt(90s) indicated that ULPt was composed of discontinuous ultrathin film of Pt and nano-particles with thick density. Pt-coated area was consisted of two regions: darker area showed that the core of Pt nano-particle was formed, and the other lighter area was corresponding to ultra-thin discontinuous layer. As a result, thick density of Pt nanostructure was achieved by the PLD method. Average of particle size at darker area was about $3.5 \mathrm{~nm}$. By contrast, boundary between Pt and carbon became unclear on the ULPt(120s). It means 


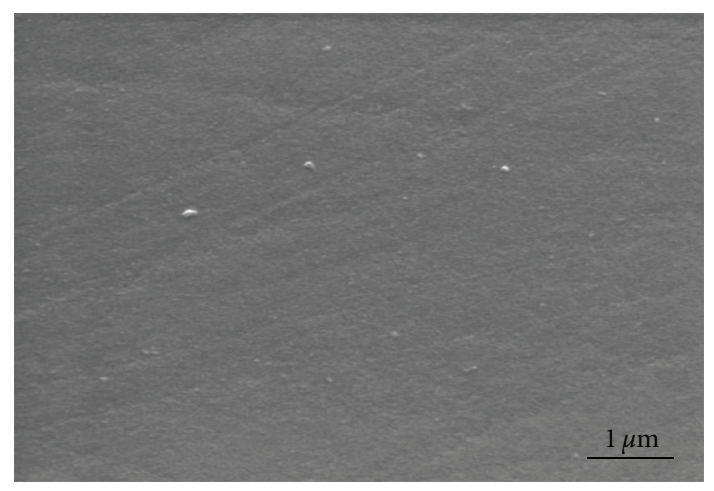

(a)

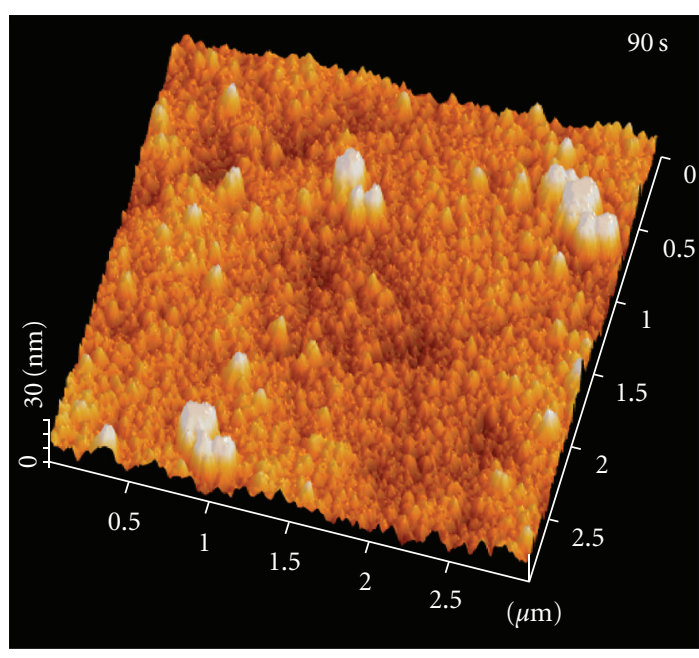

(b)

FIGURE 1: FE-SEM image (a) and AFM image (b) of ULPt(90 s). FE-SEM image was observed at 30,000 magnification, and AFM image was observed in $3 \mu \mathrm{m} \times 3 \mu \mathrm{m}$ range.

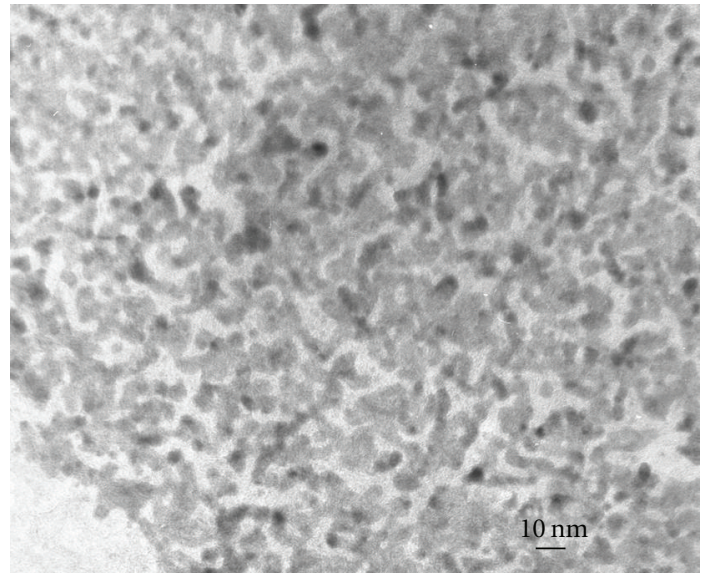

(a)

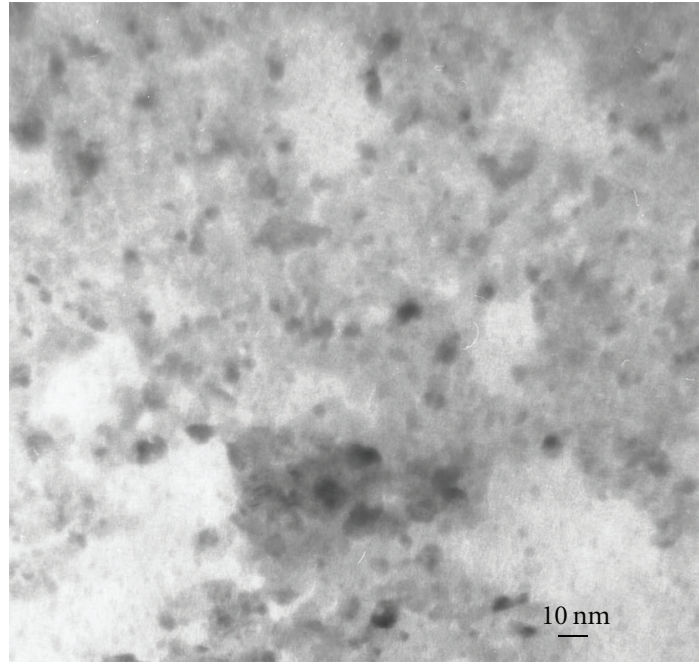

(b)

Figure 2: Transmission electron micrograph (TEM) images of ULPt(90 s): (a) and ULPt(120 s): (b).

that ultrathin film layer was covered on all the surface of GC substrate. These results were confirmed with Ra analyzed by AFM described above since Ra on ULPt(120s) was lower than that on $\operatorname{ULPt}(90 \mathrm{~s})$. In fact, $\operatorname{ULPt}(120 \mathrm{~s})$ had a flat surface since the thin Pt film covered on the substrate, and ULPt(90s) had nanosize islands consisting of Pt nanoparticles.

We investigated $\operatorname{ULPt}(90 \mathrm{~s})$ by XPS using $\mathrm{C}(1 \mathrm{~s})$ as an internal reference $(284.5 \mathrm{eV})$. Atomic concentration of Pt was calculated as about $30 \%$, when we compared $1 \mathrm{~s}$ of carbon and $4 \mathrm{f}$ of platinum. Figure 3 shows the high-resolution XPS spectrum of $\mathrm{Pt}(4 \mathrm{f})$ line. The binding energies of the $\mathrm{Pt}\left({ }^{4} \mathrm{f}_{7 / 2}\right)$ in the high-resolution spectrum was $71.5 \mathrm{eV}$, which was slightly larger than that of Pt bulk $(71.2 \mathrm{eV})$. This result indicated that the Pt particles of ULPt were in the Pt $(0)$ state and positive shift of the binding energy was due to the size effect of small particles [21].

Electrochemical characteristics of ULPt on the GC electrodes were studied. Figure 4 shows cyclic voltammograms (CVs) in $0.5 \mathrm{M}$ sulfuric acid solution which was bubbled with $\mathrm{N}_{2}$ gas for 30 minutes before the measurement. The potential of WE was ranged from 0.05 to $1.3 \mathrm{~V}$ versus RHE. CVs of ULPt were similar to that of bulk Pt. Some typical shapes attributed to $\mathrm{Pt}$ were observed on CVs: reduction of the oxide layer $(\mathrm{Or})$, formation of adsorbed oxygen or a platinum oxide layer $(\mathrm{O} a)$, the oxidation of hydrogen (reduction of absorbed hydrogen; $\mathrm{H} r$ ), and formation of absorbed hydrogen $(\mathrm{Ha} a$. The peak height of $\mathrm{H} r$ and $\mathrm{Ha}$ 


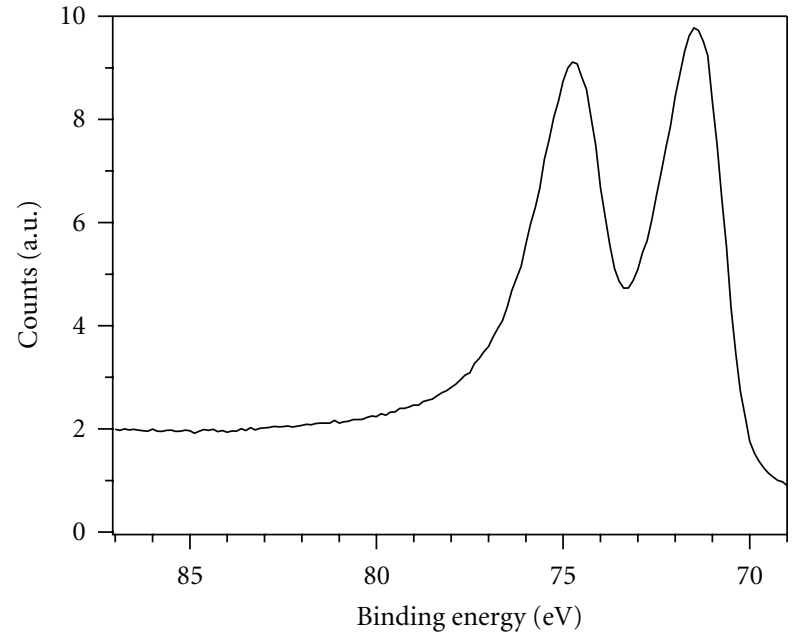

FIgUre 3: High-resolution XPS spectrum of $\mathrm{Pt}(4 \mathrm{f})$ line on $\mathrm{ULPt}(90 \mathrm{~s})$.

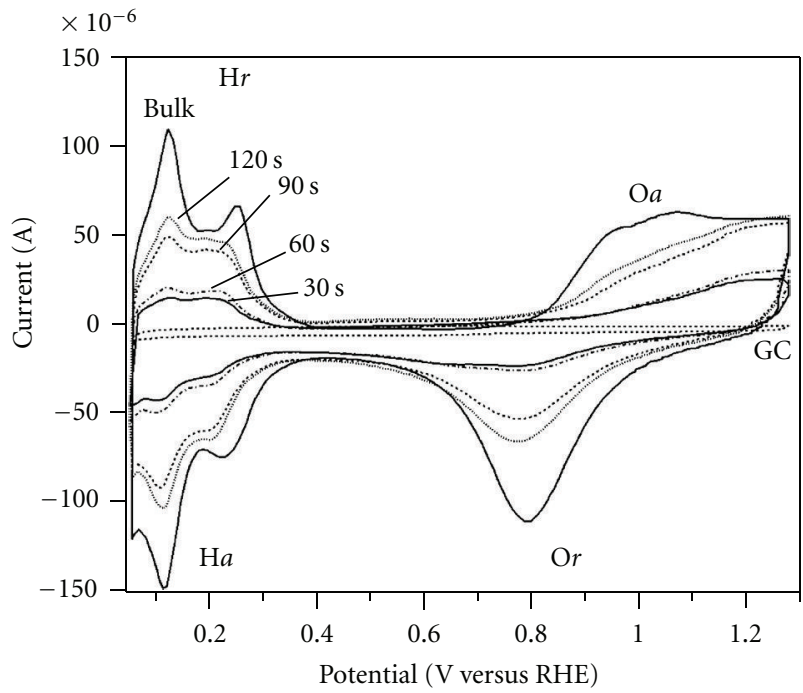

Figure 4: CVs of GC, ULPt(30s-120s), and bulk Pt in $0.5 \mathrm{M}$ sulfuric acid solution. The potential of the WE was scanned from 0.05 to $1.3 \mathrm{~V}$ versus RHE with the sweep rate of $50 \mathrm{mV} / \mathrm{s}$.

increased with the deposition time. This characteristic was corresponding to active surface area of $\mathrm{Pt}$ since the Pt-coated area increased with the deposition time. Pt active area $\left(S_{\mathrm{Pt}}\right)$ was calculated using following equation:

$$
S_{\mathrm{Pt}}=\int i \times \frac{d t}{Q_{\mathrm{Pt} 0}},
$$

here, $i, d t$ and $Q_{\text {Pto }}$ were current, time, and theoretical charge amount of bulk Pt $\left(210 \mu \mathrm{C} / \mathrm{cm}^{2}\right)$, respectively. $S_{\mathrm{Pt}}$ on $\operatorname{ULPt}(30 s-120 \mathrm{~s})$ was listed on Table 2. $S_{\mathrm{Pt}}$ increased with the deposition time. The roughness factor $(\rho)$ was defined as $S_{\mathrm{Pt}} /$ geometric area, and $\rho$ on ULPt $(90 \mathrm{~s})$ was calculated as 6.5 on assuming that the nano-particles were two-dimensionally dispersed, the Pt coverage area per unit area was approached to the Pt content determined by XPS analysis $(\mathrm{Pt} / \mathrm{C}=0.3)$.
TABle 2: Pt active area $\left(S_{\mathrm{Pt}}\right)$ corresponding to the deposition time calculating by using CVs in $0.5 \mathrm{M}$ sulfuric acid solution as shown in Figure 4 .

\begin{tabular}{lc}
\hline Sample & $S_{\mathrm{Pt}}\left(\mathrm{cm}^{2}\right)$ \\
\hline $\operatorname{ULPt}(30 \mathrm{~s})$ & 0.29 \\
$\mathrm{ULPt}(60 \mathrm{~s})$ & 0.40 \\
$\mathrm{ULPt}(90 \mathrm{~s})$ & 0.88 \\
$\mathrm{ULPt}(120 \mathrm{~s})$ & 1.06 \\
\hline
\end{tabular}

This value was ascribed to nanostructures and was higher than that of substrates prepared by other methods ( $\rho=0.2-$ 1.2) $[22]$.

Hydrogen peroxide is quite important material to detect biomaterials, since there are many oxidase-based biosensors. Additionally, a highly sensitive detection of hydrogen peroxide is anticipated since hydrogen peroxide is known as a stress marker. ULPt might have potential to decrease oxidation potential and increase the oxidation current for hydrogen peroxide because of its catalytic activity of Pt nanostructure. We observed CVs of GC substrate, ULPt(30 s$120 \mathrm{~s}$ ), and bulk Pt in $1 / 15 \mathrm{M}$ phosphate buffer solution with and without $1 \mathrm{mM}$ hydrogen peroxide. The potential of WE ranged from 0.1 to $0.9 \mathrm{~V}$ versus $\mathrm{Ag} / \mathrm{AgCl}$.

Figure 5(a) shows the CVs without hydrogen peroxide and the current increased with deposition time. The magnitude of the current on GC was much smaller compared with other electrodes. Figure 5(b) shows the CVs with hydrogen peroxide. GC electrode did not have any oxidation peaks, which means that GC electrode have low detection sensitivity for hydrogen peroxide in this potential range. Bulk Pt electrode had an oxidation peak at $0.49 \mathrm{~V}$ versus $\mathrm{Ag} / \mathrm{AgCl}$. On the other hand, potential at oxidation peak of ULPt(30s-120s) shifted approximately $100 \mathrm{mV}$ lower. In particular, ULPt(90s) had the maximum oxidation current and the minimum oxidation potential $(0.36 \mathrm{~V}$ versus $\mathrm{Ag} / \mathrm{AgCl})$. Oxidation current of ULPt(90s) was larger than that of bulk Pt despite the low Pt content (30\%). This characteristic had reproducibility. The characteristics were caused by the surface roughness and catalytic activity of nanostructures. ULPt consisted of Pt nanoparticles and nanoparticles-assembled islands at lower than $90 \mathrm{sec}$, and formed continuous ultrathin layer at $120 \mathrm{sec}$. This continuous ultrathin layer $(\operatorname{ULPt}(120 \mathrm{~s}))$ decreased the catalytic activity.

$\mathrm{ULPt}(90 \mathrm{~s})$ was applied for the detector of micro-flow injection analysis $(\mu$-FIA). The $\mathrm{WE}$ was set to $0.4 \mathrm{~V}$ versus $\mathrm{Ag} / \mathrm{AgCl}$, and the flow rate was $10 \mu \mathrm{L} / \mathrm{min}$. As the result of 50 times injection of $0.1 \mathrm{mM} \mathrm{H}_{2} \mathrm{O}_{2}$, the electrode response was stabilized with Relative Standard Deviation (RSD) of 3.3\%. These data show that the ULPt(90s) had potential of highly sensitive detector for $\mathrm{H}_{2} \mathrm{O}_{2}$ with low Pt content prepared by simple PLD method.

\section{Conclusion}

We studied the electrochemical responses of ULPt formed by the PLD method. The AFM images showed smooth surface 


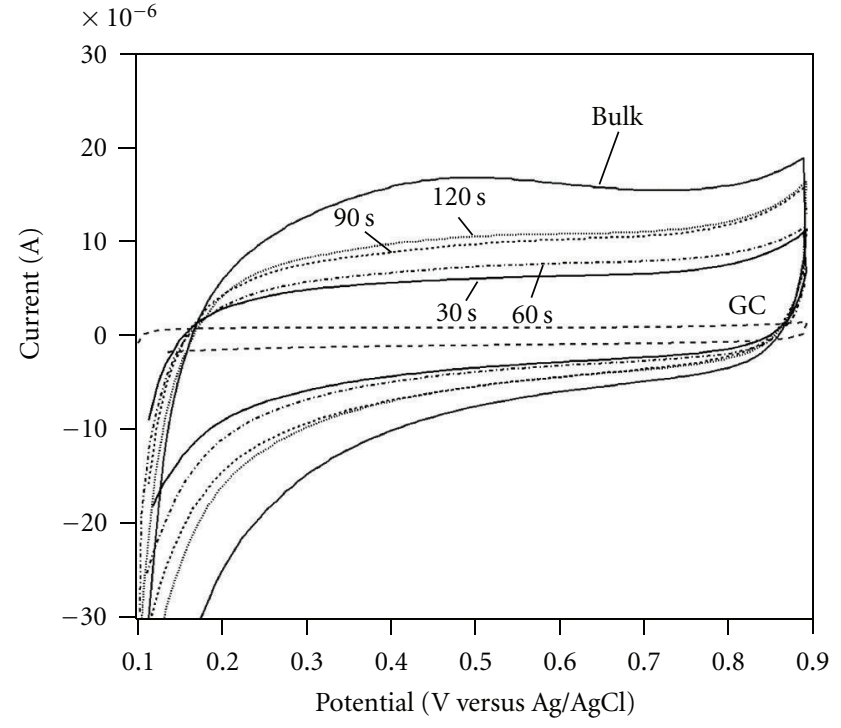

(a)

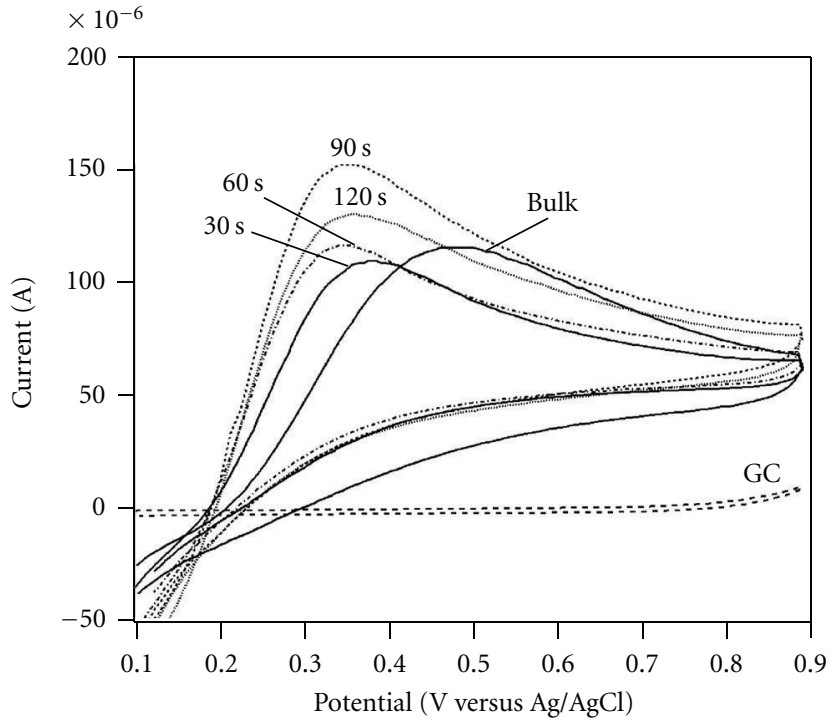

(b)

Figure 5: CVs of GC, ULPt(30s-120s), and bulk Pt in 1/15 M phosphate buffer solution without (a) and with (b) 1 mM hydrogen peroxide. The potential of the $\mathrm{WE}$ was scanned from 0.1 to $0.9 \mathrm{~V}$ versus $\mathrm{Ag} / \mathrm{AgCl}$ with the sweep rate of $50 \mathrm{mV} / \mathrm{s}$.

of ULPt. The surface roughness changed at sub-nm level after the deposition. The TEM images showed discontinuous ultrathin layer of Pt and nano-particles. The XPS analysis indicated ULPt was in the $\mathrm{Pt}(0)$ state. CVs of ULPt in $0.5 \mathrm{M}$ sulfuric acid solution were similar to that of bulk $\mathrm{Pt}$, and the peak height of hydrogen absorption/desorption increased with the deposition time. Electrochemical activity for oxidizing hydrogen peroxide using $\operatorname{ULPt}(90 \mathrm{~s})$ achieved to overcome that of bulk $\mathrm{Pt}$, at the point of the oxidation potential and oxidation current. This fast and easily prepared low-cost electrode had the potential to replace a conventional bulk metal electrode. Further study to improve the performance for detecting hydrogen peroxide and its application is in progress.

\section{Acknowledgment}

This paper was supported by The Ministry of Education, Culture, Sports, Science, and Technology (MEXT), Japan (Grant in Aid for Young Scientist (B), no. 21710134).

\section{References}

[1] O. Niwa, T. Horiuchi, M. Morita, T. Huang, and P. T. Kissinger, "Determination of acetylcholine and choline with platinumblack ultramicroarray electrodes using liquid chromatography with a post-column enzyme reactor," Analytica Chimica Acta, vol. 318, no. 2, pp. 167-173, 1996.

[2] A. Kicela and S. Daniele, "Platinum black coated microdisk electrodes for the determination of high concentrations of hydrogen peroxide in phosphate buffer solutions," Talanta, vol. 68, no. 5, pp. 1632-1639, 2005.

[3] H. Xu, L. Zeng, S. Xing et al., "Highly ordered platinumnanotube arrays for oxidative determination of trace
arsenic(III)," Electrochemistry Communications, vol. 10, no. 12, pp. 1893-1896, 2008.

[4] J. Wang, N. V. Myung, M. Yun, and H. G. Monbouquette, "Glucose oxidase entrapped in polypyrrole on high-surfacearea Pt electrodes: a model platform for sensitive electroenzymatic biosensors," Journal of Electroanalytical Chemistry, vol. 575, no. 1, pp. 139-146, 2005.

[5] M. R. Callstrom, T. X. Neenan, R. L. McCrecry, and D. C. Alsmeyer, "Doped glassy carbon materials (DGC): lowtemperature synthesis, structure, and catalytic behavior," Journal of the American Chemical Society, vol. 112, no. 12, pp. 4954-4956, 1990.

[6] N. L. Pocard, D. C. Alsmeyer, R. L. McCreery, T. X. Neenan, and M. R. Callstrom, "Doped glassy carbon: a new material for electrocatalysis," Journal of Materials Chemistry, vol. 2, no. 8, pp. 771-784, 1992.

[7] N. L. Pocard, D. C. Alsmeyer, R. L. McCreery, T. X. Neenan, and M. R. Callstrom, "Nanoscak platinum (0) clusters in glassy carbon: synthesis, characterization, and uncommon catalytic activity," Journal of the American Chemical Society, vol. 114, no. 2, pp. 769-771, 1992.

[8] T. You, O. Niwa, M. Tomita, and S. Hirono, "Characterization of platinum nanoparticle-embedded carbon film electrode and its detection of hydrogen peroxide," Analytical Chemistry, vol. 75, no. 9, pp. 2080-2085, 2003.

[9] T. You, O. Niwa, Z. Chen, K. Hayashi, M. Tomita, and S. Hirono, "An amperometric detector formed of highly dispersed Ni nanoparticles embedded in a graphite-like carbon film electrode for sugar determination," Analytical Chemistry, vol. 75, no. 19, pp. 5191-5196, 2003.

[10] J. Fitz-Gerald, S. Pennycook, H. Gao, and R. K. Singh, "Synthesis and properties of nanofunctionalized particulate materials," Nanostructured Materials, vol. 12, no. 5-8, pp. 1167-1171, 1999.

[11] S. Murugesan, P. Kuppusami, N. Parvathavarthini, and E. Mohandas, "Pulsed laser deposition of anatase and rutile TiO2 
thin films," Surface and Coatings Technology, vol. 201, no. 18, pp. 7713-7719, 2007.

[12] P. T. Murray and E. Shin, "Formation of silver nanoparticles by through thin film ablation," Materials Letters, vol. 62, no. 28, pp. 4336-4338, 2008.

[13] S. Kaneko, K. Akiyama, H. Funakubo, and M. Yoshimoto, "Strain-amplified structural modulation of Bi-cuprate high-Tc superconductors," Physical Review B, vol. 74, no. 5, Article ID 054503, 2006.

[14] U. P. Muecke, K. Akiba, A. Infortuna, T. Salkus, N. V. Stus, and L. J. Gauckler, "Electrochemical performance of nanocrystalline nickel/gadolinia-doped ceria thin film anodes for solid oxide fuel cells," Solid State Ionics, vol. 178, no. 33-34, pp. 1762-1768, 2008.

[15] D. E. Kim, S. M. Lee, I. J. Jeon, and M. Yanagihara, "Characterization of a multilayer soft X-ray reflector fabricated by pulsed laser deposition," Applied Surface Science, vol. 127-129, pp. 531-535, 1998.

[16] E. Rodríguez, E. Jimenez, L. A. Padilha et al., " $\mathrm{SiO}_{2} / \mathrm{PbTe}$ quantum-dot multilayer production and characterization," Applied Physics Letters, vol. 86, no. 11, Article ID 113117, pp. 1-3, 2005.

[17] Y. Suda, T. Ono, M. Akazawa, Y. Sakai, J. Tsujino, and N. Homma, "Preparation of carbon nanoparticles by plasmaassisted pulsed laser deposition method-size and binding energy dependence on ambient gas pressure and plasma condition," Thin Solid Films, vol. 415, no. 1-2, pp. 15-20, 2002.

[18] M. Matsubara, T. Yamaki, H. Itoh, H. Abe, and K. Asai, "Preparation of $\mathrm{TiO}_{2}$ nanoparticles by pulsed laser ablation: ambient pressure dependence of crystallization," Japanese Journal of Applied Physics, vol. 42, no. 5 A, pp. L479-L481, 2003.

[19] S. Kaneko, Y. Shimizu, and S. Ohya, "Preparation of BiSr$\mathrm{CaCuO}$ multilayers by use of slower Q-switched $266 \mathrm{~nm}$ YAG laser," Japanese Journal of Applied Physics, vol. 40, no. 8, pp. 4870-4873, 2001.

[20] S. Kaneko, Y. Shimizu, H. Yuasa, and S. Ohya, " $\mathrm{Bi}_{2} \mathrm{Sr}_{2} \mathrm{Ca}_{1} \mathrm{Cu}_{2} \mathrm{OX}$ film prepared using $266 \mathrm{~nm}$ YAG laser," Physica C, vol. 378-381, no. 2, pp. 1270-1273, 2002.

[21] T. T. P. Cheung, "X-ray photoemission of small platinum and palladium clusters," Surface Science, vol. 140, no. 1, pp. 151164, 1984.

[22] P. Karam and L. I. Halaoui, "Sensing of $\mathrm{H}_{2} \mathrm{O}_{2}$ at low surface density assemblies of $\mathrm{Pt}$ nanoparticles in polyelectrolyte," Analytical Chemistry, vol. 80, no. 14, pp. 5441-5448, 2008. 


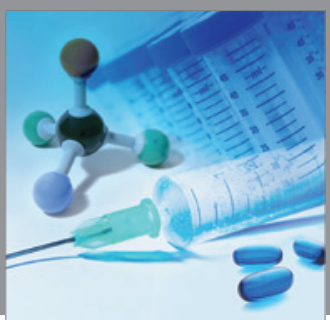

International Journal of

Medicinal Chemistry

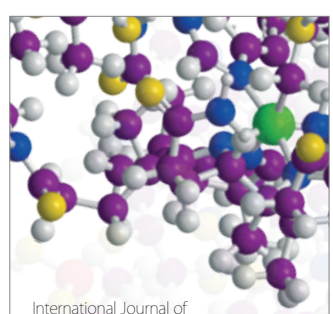

Carbohydrate Chemistry

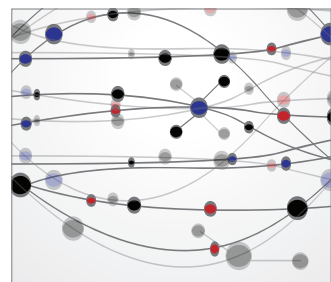

The Scientific World Journal
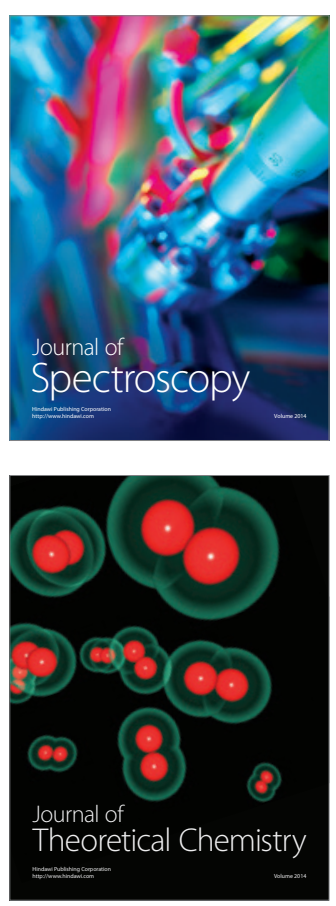
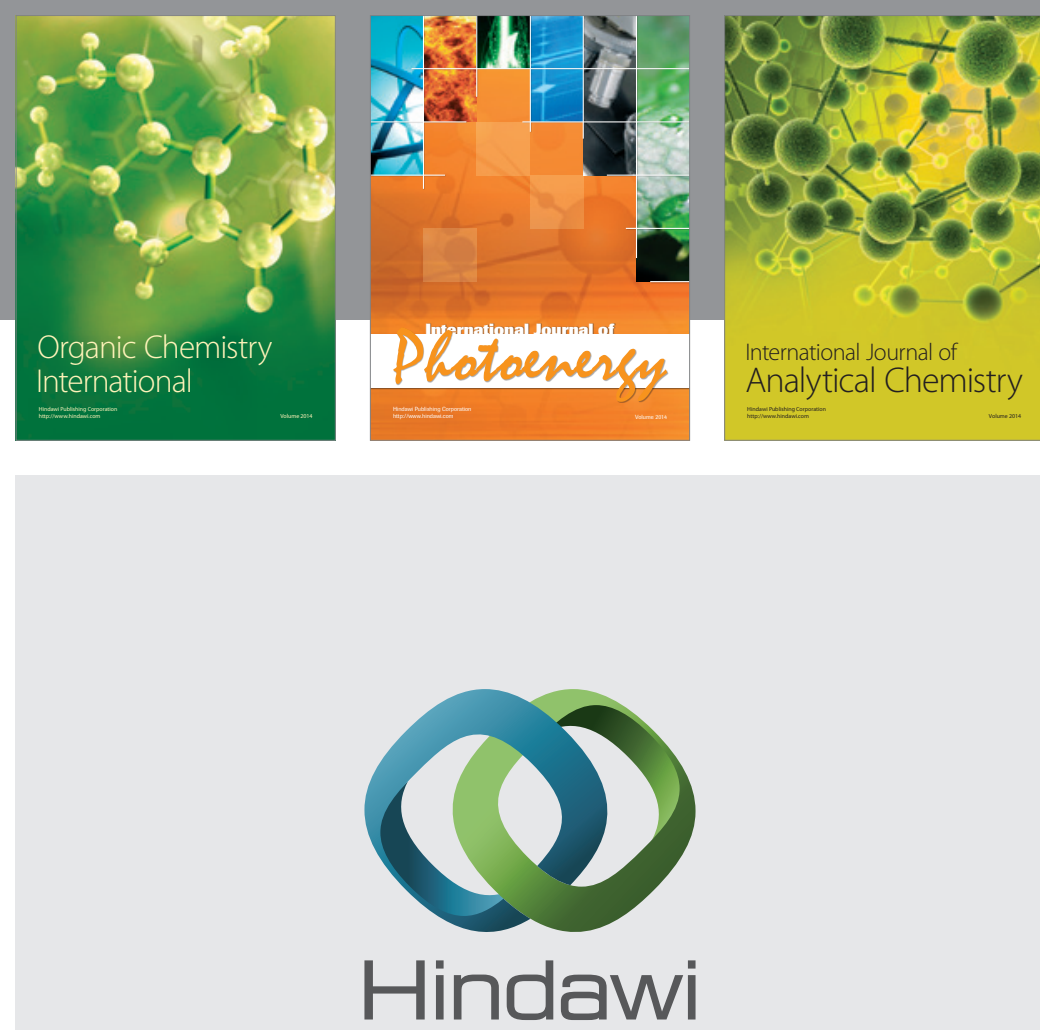

Submit your manuscripts at

http://www.hindawi.com
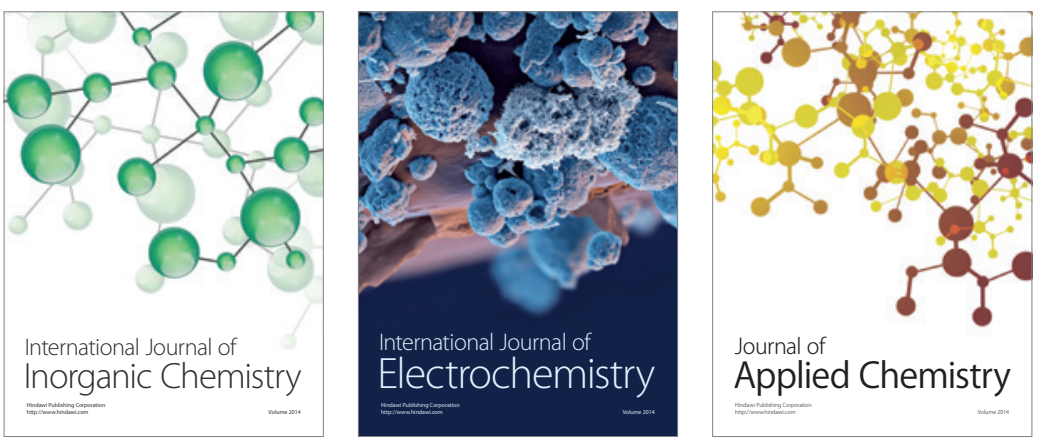

Journal of

Applied Chemistry
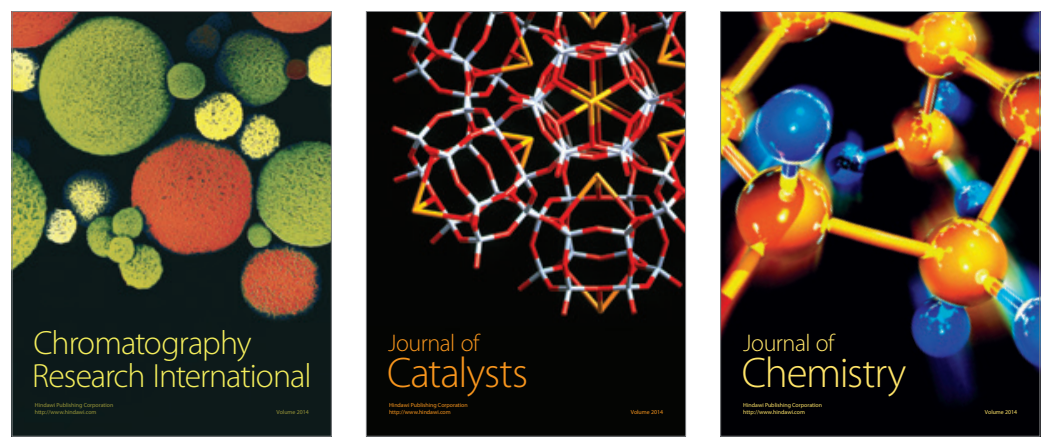
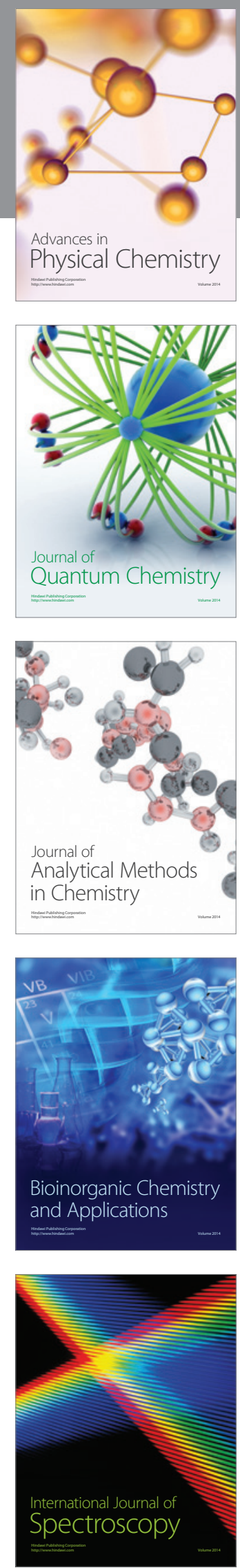